\title{
Salty anomalies forced by Tehuantepec and Papagayo gap winds: Aquarius observations
}

\author{
Semyon A. Grodsky ${ }^{\mathrm{a},}{ }^{*}$, James A. Carton ${ }^{\mathrm{a}}$ and Abderrahim Bentamy ${ }^{\mathrm{b}}$ \\ ${ }^{a}$ Department of Atmospheric and Oceanic Science, University of Maryland, College Park, MD, USA \\ ${ }^{b}$ Institut Francais pour la Recherche et l'Exploitation de la Mer, Centre Bretagne - ZI de la Pointe du Diable, \\ Plouzané, France \\ *: Corresponding author : Semyon A. Grodsky, email address : mailto:senya@atmos.umd.edu
}

\begin{abstract}
:
In the presence of stable near-surface haline stratification, intermittent cold sea surface temperature (SST, upwelling) events produced by gap winds off the Central American Pacific coast should be accompanied by uplifts of saltier water. We illustrate that Aquarius satellite sea surface salinity (SSS) captures these high SSS events. In boreal winter when the intense gap winds are frequent, two tongues of anomalously salty water develop off the Gulfs of Tehuantepec and Papagayo. During that season the average SSS in the meridionally oriented Tehuantepec tongue is about 0.4 psu saltier than the background SSS. The zonally elongated Papagayo tongue stands out even more strongly, being 1-2 psu saltier than SSS in the neighbouring Panama Bight. The spatial locations and orientations of the salty tongues closely correspond to the locations and orientations of the cool SST tongues, suggesting they have similar governing mechanisms.
\end{abstract}

\section{Introduction}

The Central American Pacific (CAP) seasonal upwelling in the Gulfs of Tehuantepec, Papagayo and Panama Bight has been studied extensively (e.g. Stumpf and 
29 Legeckis, 1977; Legeckis 1988, and others). This regional upwelling occurs from

30 November to March in response to episodic gale-force offshore jet-like winds, which

31 amplify in response to a combination of the cool synoptic-scale systems and undulations

32 in the strength of trade winds in the Atlantic sector over the Gulf of Mexico and

33 Caribbean (e.g. Chelton et al., 2000a,b; Brennan et al., 2010). The northerly and easterly

34 winds associated with these synoptic systems are blocked by the Central American

35 Cordillera, except for winds tunneling at the three gaps at the Isthmus of Tehuantepec

36 (T), the Lake of Nicaragua (Papagayo jet, PP), and Panama Channel (PA, see Fig.1).

37 Typically the resulting air flow jets are about $200 \mathrm{~km}$ wide, extend several hundred

38 kilometers (up to $500 \mathrm{~km}$ ) downstream, and the period of intensified air flow lasts for 3 to

3910 days (McCreary et al., 1989; Brennan et al, 2010).

40 These gap wind jets induce a remarkable oceanic response seen in low SST

41 patterns that are spatially co-aligned with the jets (Legeckis, 1988). These winds also

42 force pronounced intra-seasonal variability in the sea surface height (SSH) that is

43 organized into trains of eddies propagating southwestward at speeds of $15-17 \mathrm{~cm} \mathrm{~s}^{-1}$ from

44 Tehuantepec and Papagayo (McCreary et al., 1989; Giese et al., 1994; Chang et al.,

45 2012). All of these features generate very complex dynamics, reflected in the

46 thermohaline structure, which shows not only significant temporal variation but also

47 strong salinity fronts resulting from interaction between cold and warm core eddies

48 (Brenes et al., 1998).

49 The wind-induced upwelling physics producing the cool SSTs off the CAP coast

50 should also produce high SSS because the ocean mixed layer has lower salinity than the

51 submixed layer water due to dilution by local rainfall (Alory et al., 2012). The freshwater 
52 pool disruptions in the Panama Bight have been linked to the gap winds and associated

53 upwelling that brings cold and salty water to the surface (Reul et al., 2014). The recent

54 availability of remotely sensed SSS (e.g. Lagerloef et al., 2012) significantly improves

55 our ability to monitor this variable and is used in this paper to detect the SSS signature of

56 the ocean response to gap wind jets. Our analysis predominantly focuses on the seasonal

57 mean patterns because the combination of spatial and temporal sampling of satellite SSS

58 doesn't fully resolve the ocean response to individual wind events.

59 2. Data

60 This study mostly relies on measurements of satellite surface salinity,

61 temperature, and winds. The main SSS data set used in this study is the daily level 3

62 version 2.8.1 Aquarius SSS beginning 25 August, 2011 and extending through 17

63 February 2014, obtained from the NASA Jet Propulsion Laboratory Physical

64 Oceanography Distributed Active Archive Center on a $1^{\circ} \times 1^{\circ}$ grid (Lagerloef et al.,

65 2012). These data now span three boreal winter seasons (when the gap winds are strong).

66 Although daily Aquarius SSS is available, complete spatial coverage is available only for

67 weekly averages. To emphasize features present during all years, the seasonal

68 climatology of SSS is evaluated using Fourier series truncated after the annual and

69 semiannual harmonics. It is reasonable to estimate the SSS climatology because of the

70 dominance of the annual cycle in the tropics (e.g. Xie and Carton, 2004). We also

71 compare daily SST and SSS in a spatially averaged region, recognizing that such a daily

72 SSS time series will be quite noisy. Surface winds are based on the Advanced

73 SCATterometer (ASCAT), which are available at $0.25^{\circ} \times 0.25^{\circ}$ resolution (Bentamy and

74 Croize-Fillon, 2012) since November 2008. SST is also available at a resolution of 
$750.25^{\circ} \times 0.25^{\circ}$ based on the NOAA optimum interpolation analysis of Reynolds et al.

76 (2007). To evaluate the surface salt flux we use the monthly OaFlux evaporation analysis

77 of Yu (2007) available on a $1^{\circ} \times 1^{\circ}$ grid and the Tropical Rainfall Measuring Mission

78 monthly mean precipitation (trmm.gsfc.nasa.gov).

79 3. Results

80 The freshest SSS in the tropical Pacific occurs in the Panama Bight due to

81 abundant rainfall and a pattern of surface currents that trap the fresh water locally (Alory

82 et al., 2012). Further along the north CAP coast, SSS is relatively fresh (about 33 psu

83 south of $15^{\circ} \mathrm{N}$ ) in summer and fall due to the seasonal northward shift of the Intertropical

84 Convergence Zone (ITCZ) and cumulating impact of the surface freshwater forcing (Fig.

85 1e,g). During the dry boreal winter, as the ITCZ is displaced to the south, SSS increases

86 with latitude along the CAP coast (Fig. 1a). In boreal spring, SSS increases even more,

87 up to $35 \mathrm{psu}$, in a near-coastal tongue of salty water stretching down to $10^{\circ} \mathrm{N}$ (Fig. 1c).

88 This salty tongue is probably produced by southeastward salt advection by the

89 southeastern extension of the shallow geostrophic California Current (Kessler, 2006).

90 In boreal winter, two additional tongues of salty water develop off the Gulfs of

91 Tehuantepec and Papagayo (Fig. 1a). SSS contrast in the meridionally oriented

92 Tehuantepec tongue is about 0.4 psu. The zonally elongated Papagayo tongue is 1 to 2

93 psu saltier than the mean SSS in the Panama Bight. It is worth noting that the impact on

94 water density of an increase in salinity by 1 psu is the equivalent of a $3^{\circ} \mathrm{C}$ drop in SST.

95 So the SSS and SST changes induced by the gap winds have similar sized effects on

96 mixed layer density, at least for Papagayo. 
The orientation of the gap winds that develop in boreal fall and winter is defined

98 by the terrestrial elevation profiles of the gaps in the Cordillera. These winds intensify

99 from November to March and produce remarkable seasonal cooling of SST in the

100 Tehuantepec and Papagayo upwelling regions (Fig. 1b). In winter, this SST cooling is

101 accompanied by increasing SSS. During other seasons (when the gap winds are not as

102 intense as in boreal winter) the salty tongues are weaker and are not detectable by the

103 Aquarius. Although the gap winds are also present in the Panama Bight (seen in SST

104 maps in Fig. 1b), an expected increase in the seasonal SSS is not observed there (in

105 contrast to transient disruptions of the fresh pool reported by Reul et al. (2014)). This

106 absence, we believe, is due to the effects of land contamination on the Aquarius SSS

107 retrievals, which result in a negative SSS bias.

108 The salty tongues off the CAP coast develop late each fall and persist to early

109 spring (Fig. 2a). Their location corresponds with the location of cool SST tongues

110 suggesting a similarity in mechanisms responsible for the two types of anomalies.

111 Because both the salty and cold SST tongues are forced by strong gap winds, the former

112 may originate due to stronger evaporation. But, closer inspection of the net surface salt

113 flux (evaporation minus precipitation, E-P, in Fig. 2b) doesn’t reveal patterns of higher E-

114 P spatially collocated with the gap winds. This unexpected feature is explained by

115 changes in the sea surface saturated humidity, which decreases over cold water and leads

116 to decreased air-sea humidity difference. This humidity effect counteracts the effect of

117 the wind increase, thus attenuating spatial anomalies of E-P otherwise expected in

118 response to the gap winds. 
120 wind jets due to the entrainment of cooler water from below the mixed layer. This

121 entrainment cooling, $w_{e} \Delta T_{e}$, occurs due to the upward cross-isopycnal velocity, $w_{e}$, that

122 entrains colder water $\left(\Delta T_{e}<0\right)$ into the shallow $10-50 \mathrm{~m}$ mixed layer. Here we suggest that

123 the same entrainment mechanism, $w_{e} \Delta S_{e}$, leads to increasing mixed layer salinity in the

124 CAP region where strong salinity stratification results from heavy local rainfall and more

125 salty water $\left(\Delta S_{e}>0\right)$ locates below the mixed layer. This mechanism is similar to that

126 producing salty signature of strong wind forcing over river plumes (e.g. Grodsky et al., 127 2012).

128 Entrainment velocity across the base of the mixed layer has two components,

129 mixed layer deepening and vertical velocity, $w_{e}=d h / d t+w$. The mixed layer depth $(h)$

130 may deepen in time ( $d h / d t)$ due to wind-induced stirring. Also, a positive (upward)

131 vertical velocity $(w)$ is induced by positive Ekman pumping, which is most prominent on

132 the left side of the wind jet where the wind stress curl is positive. The central axes of the

133 Tehuantepec SST and SSS anomalies are located along the axes of the maximum wind

134 speed, which is where the Ekman pumping is a minimum (Figs. 2c, 2d) suggesting that at

135 this location entrainment due to wind stirring dominates over entrainment due to Ekman

136 pumping. In contrast the central axes of the Gulf of Papagayo SST and SSS anomalies are

137 shifted left of the maximum wind speed suggesting that for this region wind stirring and

138 Ekman pumping both contribute to entrainment.

139 As illustrated for the Gulf of Tahuantepec in Fig. 3a, the cool season November to

140 March is the season with frequent 3 to 10 day cool SST anomalies. Because the Aquarius

141 provides no-gap coverage only once in seven days, the corresponding time series of SSS 
142 are subject to considerable sampling errors. Nevertheless, a comparison of the time series

143 shows that many of the 3 to 10 day cool SST anomalies correspond to high SSS (Fig. 3a)

144 and that the correspondence is higher when the data counts are higher. As a result the

145 two time series are negatively correlated (the correlation coefficient is about -0.3 at zero

146 lag, Fig. 3b), but the correlation is reduced because of the satellite SSS sampling

147 problems. The lagged correlation of anomalous wind speed and SST is stronger, and the

148 fact that the maximum SST cooling lags behind wind speed amplification by only 1 to 2

149 days highlights the rapid response of the ocean to these wind events.

150 4. Summary

151 Rainfall off the Central American Pacific (CAP) coast dilutes the ocean mixed

152 layer, which is thus fresher than the water beneath the mixed layer. The CAP region is

153 characterized by intermittent 3-10 day gale-force wind events in boreal winter which

154 cause surface cooling in several geographically narrow regions. Using new observations

155 of SSS collected by the Aquarius satellite we show that these cool SST events coincide

156 with high SSS events.

157 In this study we focus on two regions: the Gulfs of Tehuantepec and Papagayo.

158 During boreal winter, the seasonally average SSS in the meridionally oriented

159 Tehuantepec cool tongue is about 0.4 psu saltier than the climatological average SSS.

160 The zonally elongated Papagayo tongue is 1 to 2 psu saltier than SSS in the Panama

161 Bight. The spatial location and orientation of the salty tongues closely follows those of

162 the cool SST tongues, in turn suggesting similarity of their governing mechanisms.

163 Salty signatures produced by individual gap wind events are not well sampled by

164 Aquarius. Nevertheless, a comparison of a spatially averaged index time series for the 
165 Tehuantepec index region shows some salinity events that correspond to SST events

166 (sampling issues reduce the average correlation between anomalous SST and SSS to -0.3

167 at zero lag). A similar lagged correlation of anomalous wind speed and SST shows that

168 the mixed layer is responding to the wind events with a lag of only 1 to 2 days.

169 It is still an open question whether satellite SSS is useful in coastal areas and

170 marginal seas where spatial and temporal variability occur at smaller scales and SSS

171 retrievals are more likely contaminated by the radio frequency interference and land. This

172 study along with the Gierach et al. (2013) examination of salinity in the Gulf of Mexico

173 demonstrates the usefulness of Aquarius data in this challenging near-coastal

174 environment

175 Acknowledgements This research was supported by the NASA (NNX12AF68G,

176 NNX09AF34G, and NNX10AO99G) and by TOSCA (Terre, Océan, Surfaces

177 continentales, Atmosphère) project.

$178 \quad$ References

179 Alory, G., C. Maes, T. Delcroix, N. Reul, and S. Illig (2012), Seasonal dynamics of sea

180 surface salinity off Panama: The far Eastern Pacific Fresh Pool, J. Geophys. Res.,

$181 \quad$ 117, C04028, doi:10.1029/2011JC007802.

182 Bentamy, A., and D. Croizé-Fillon (2011), Gridded Surface Wind Fields From

183 Metop/ASCAT Measurements. Int. J. Remote Sens., 33, 1729-1754.

184 Brenes, C., A. Hernandez, and A. Gutierrez (1998), Sea surface thermohaline variations

185 along the Nicaraguan Pacific coastal waters, Topicos Meteor. Oceanogr, 5, 17-25.

186 Brennan, M. J., H. D. Cobb, and R. D. Knabb (2010), Observations of Gulf of

187 Tehuantepec Gap Wind Events from QuikSCAT: An Updated Event Climatology and 
Operational Model Evaluation. Wea. Forecasting, 25, 646-658. doi: http://dx.doi.org/10.1175/2009WAF2222324.1

190 Chang, C.-H., S.-P. Xie, N. Schneider, B. Qiu, J. Small, W. Zhuang, B. Taguchi, H.

191 Sasaki, and X. Lin (2012), East Pacific ocean eddies and their relationship to

192 subseasonal variability in Central American wind jets, J. Geophys. Res., 117, C10001, 193 doi:10.1029/2011JC007315.

194 Chelton, D. B., M. H. Freilich, and S. K. Esbensen (2000a), Satellite observations of the 195 wind jets off the Pacific coast of Central America. Part I: Case studies and statistical 196 characteristics, Mon. Weather Rev., 128, 1993-2018, doi:10.1175/15200493(2000)128<1993:SOOTWJ>2.0.CO;2.

198 Chelton, D. B., M. H. Freilich, and S. K. Esbensen (2000b), Satellite observations of the 199 wind jets off the Pacific coast of Central America. Part II: Regional relationships and 200 dynamical considerations, Mon. Weather Rev., 128, 2019-2043, doi:10.1175/15200493(2000)128<2019:SOOTWJ>2.0.CO;2.

202 Gierach, M. M., J. Vazquez-Cuervo, T. Lee, and V. M. Tsontos (2013), Aquarius and 203 SMOS detect effects of an extreme Mississippi River flooding event in the Gulf of 204 Mexico, Geophys. Res. Lett., 40, 5188-5193, doi:10.1002/grl.50995.

205 Giese, B.S., J.A. Carton, and L. Holl, (1994), Sea-level variability in the eastern Pacific 206 as viewed from TOPEX altimetry and TAO hydrography, J. Geophys. Res., Special 207 Volume on TOPEX Altimetry, 24,739-24,748.

208 Grodsky, S. A., N. Reul, G. S. E. Lagerloef, G. Reverdin, J. A. Carton, B. Chapron, Y. 209 Quilfen, V. N. Kudryavtsev, and H.-Y. Kao (2012), Haline hurricane wake in the 210 Amazon/Orinoco plume: AQUARIUS/SACD and SMOS observations, Geophys. Res. 
Lett., 39, L20603, doi:10.1029/2012GL053335. http://dx.doi.org/10.1029/2012GL053335.

213 Kessler, W.S. (2006), The circulation of the eastern tropical Pacific: A review, Progr.

214 Oceanogr., 69, 181-217, http://dx.doi.org/10.1016/j.pocean.2006.03.009

215 Lagerloef, G., F. Wentz, S. Yueh, H.-Y. Kao, G. C. Johnson, and J. M. Lyman (2012),

216 Aquarius satellite mission provides new, detailed view of sea surface salinity, in State

217 of the Climate 2011, Bull. Am. Meteor. Soc., 93, S70-S71.

218 Legeckis, R. (1988), Upwelling off the Gulfs of Panama and Papagayo in the tropical

219 Pacific during March 1985, J. Geophys. Res., 93, 15485-15489,

220 doi:10.1029/JC093iC12p15485.

221 McCreary, J. P., Jr., H. S. Lee, and D. B. Enfield (1989), The Response of the Coastal

222 Ocean to Strong Offshore Winds: With Applications to Circulation in the Gulf of

223 Tehuantepec and Papagayo, J. Mar. Res., 109, 47-81.

224 Reul, N., S. Fournier, J. Boutin, O. Hernandez, C. Maes, B. Chapron, G. Alory, Y.

225 Quilfen, J. Tenerelli, S. Morisset, Y. Kerr, S. Mecklenburg, and S. Delwart (2014),

226 Sea Surface Salinity Observations from Space with the SMOS Satellite: A New

227 Means to Monitor the Marine Branch of the Water Cycle, Surv. Geoph., 35, 681 -

228 772, doi: 10.1007/s10712-013-9244-0

229 Reynolds, R. W., T. M. Smith, C. Liu, D. B. Chelton, K. S. Casey and M. G. Schlax

230 (2007), Daily High-resolution Blended Analyses for sea surface temperature. $J$.

231 Climate, 20, 5473-5496. 
232 Stumpf, H. G., and R. V. Legeckis (1977), Satellite observations of mesoscale eddy

233 dynamics in the eastern tropical Pacific Ocean, J. Phys. Oceanogr., 7, 648-658,

234 doi:10.1175/1520-0485(1977)007<0648:SOOMED>2.0.CO;2.

235 Xie, S.-P., and J. A. Carton (2004), Tropical Atlantic variability: Patterns, mechanisms,

236 and impacts, in Earth's Climate, edited by C. Wang, S. P. Xie, and J. A. Carton,

237 AGU, Washington, D. C., doi:10.1029/147GM07.

238 Yu, L. (2007), Global Variations in Oceanic Evaporation (1958-2005): The Role of the

239 Changing Wind Speed. J. Climate, 20, 5376-5390. doi:

$240 \quad$ http://dx.doi.org/10.1175/2007JCLI1714.1

241 

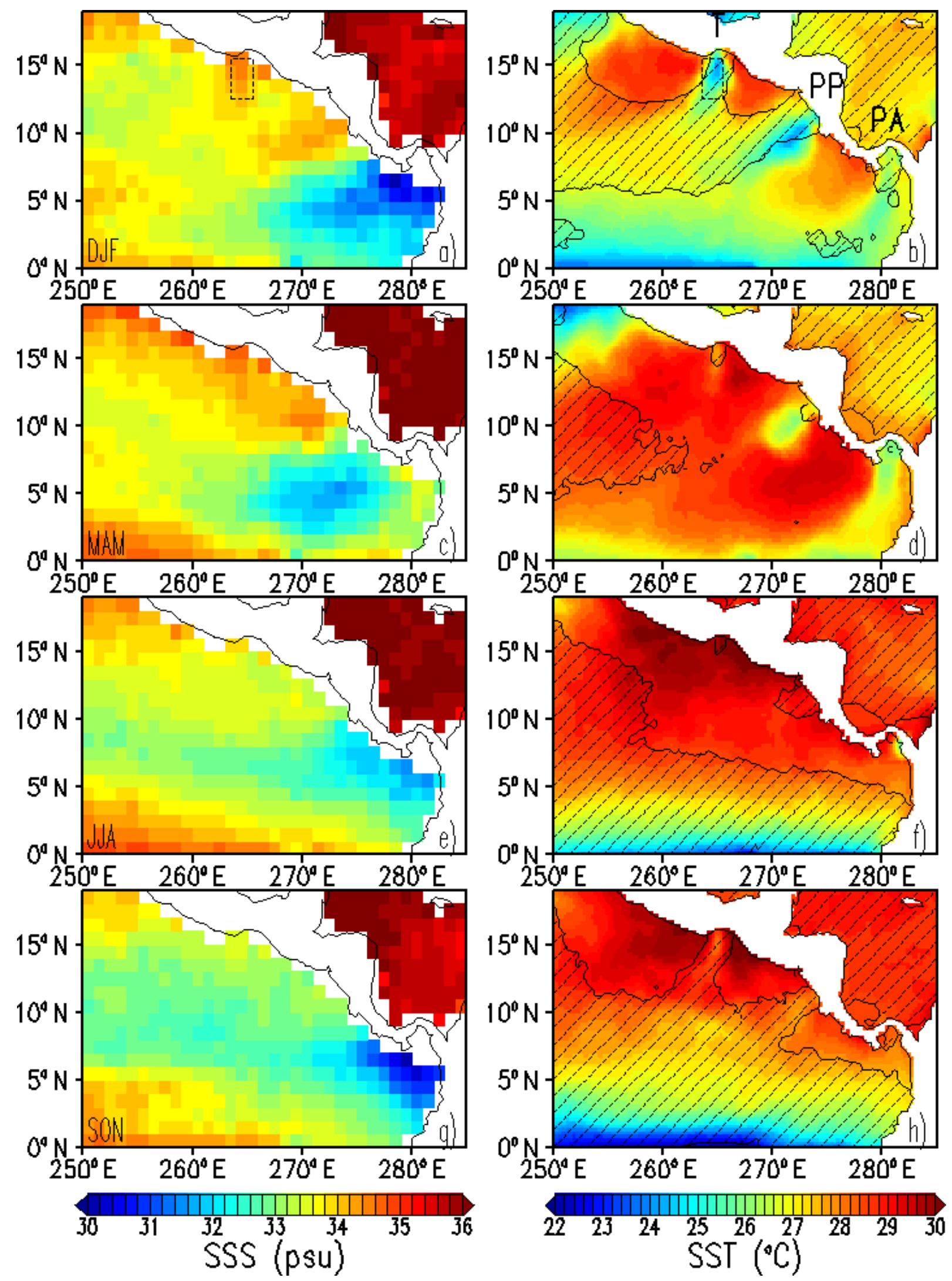
244 Figure 1. 3-month mean Aquarius SSS (left) and NOAA OI SST (right) based on the 245 Decemeber 2011 -November 2012 data. The hatched areas in the SST maps show where 246 the ASCAT wind speed was greater than $5 \mathrm{~m} \mathrm{~s}^{-1}$. Gulf of Tahuantepec index region is 247 shown in panels (a) and (b). Tehuantepec (T), Papagayo (PP), and Panama Bay (PA) 248 regions are marked in panel (b). Common 3-month abbreviations, like 'DJF' for 249 December-January-February etc., are used in (a). 

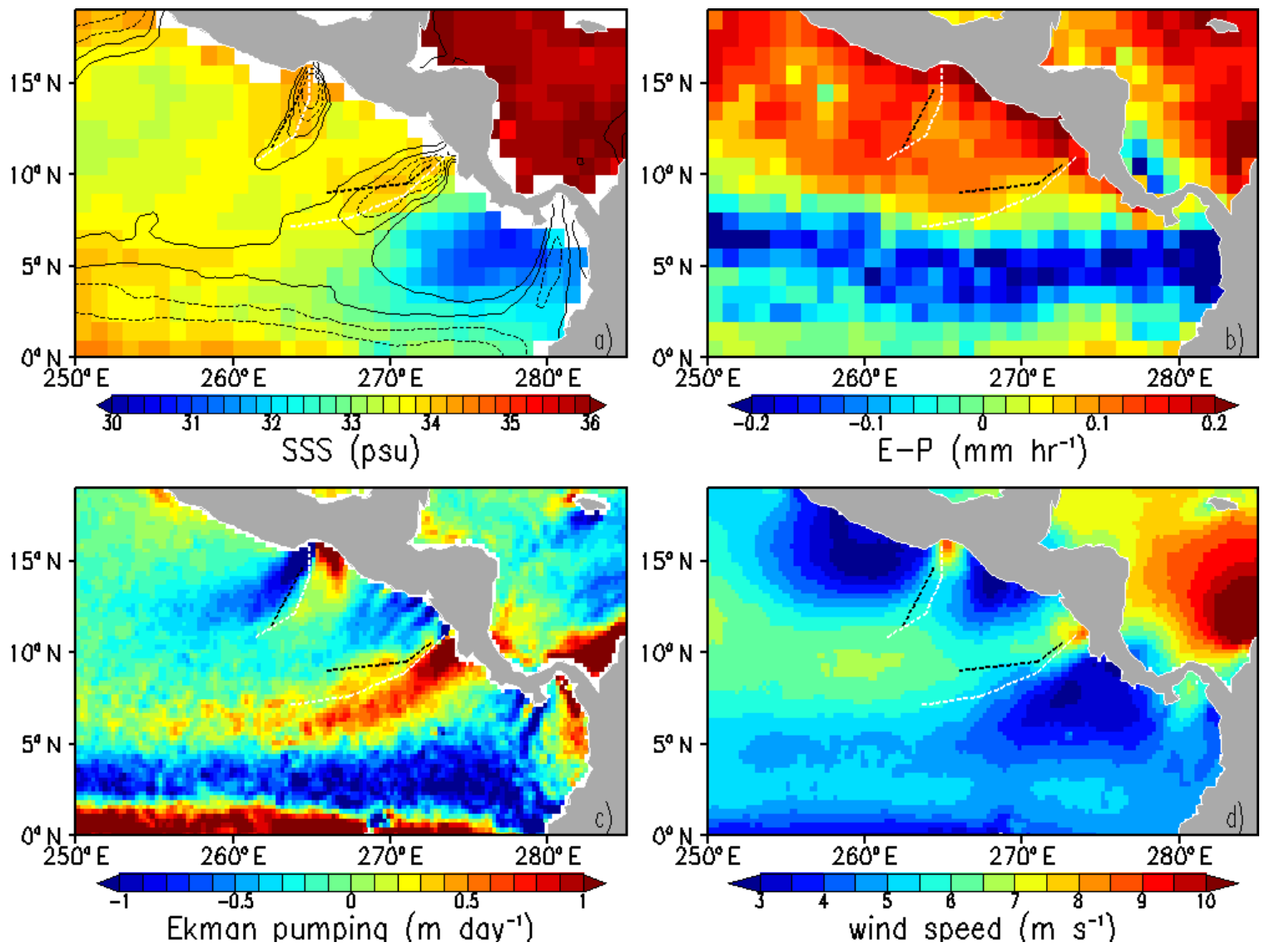

Figure 2. December-January-February (DJF) seasonal climatology based on the interval September 2011 to February 2014. (a) SSS (shaded), SST (contours, interval $=0.5^{\circ} \mathrm{C}$, 254 SST $\geq 26^{\circ} \mathrm{C}$ : solid; SST $<26^{\circ} \mathrm{C}$ : dashed). (b) Evaporation minus precipitation. (c) 255 Ekman pumping computed using ASCAT winds (upward is positive). (d) ASCAT wind speed. Centroid lines of SSS and SST signatures are shown as black and white dashed lines, respectively. 


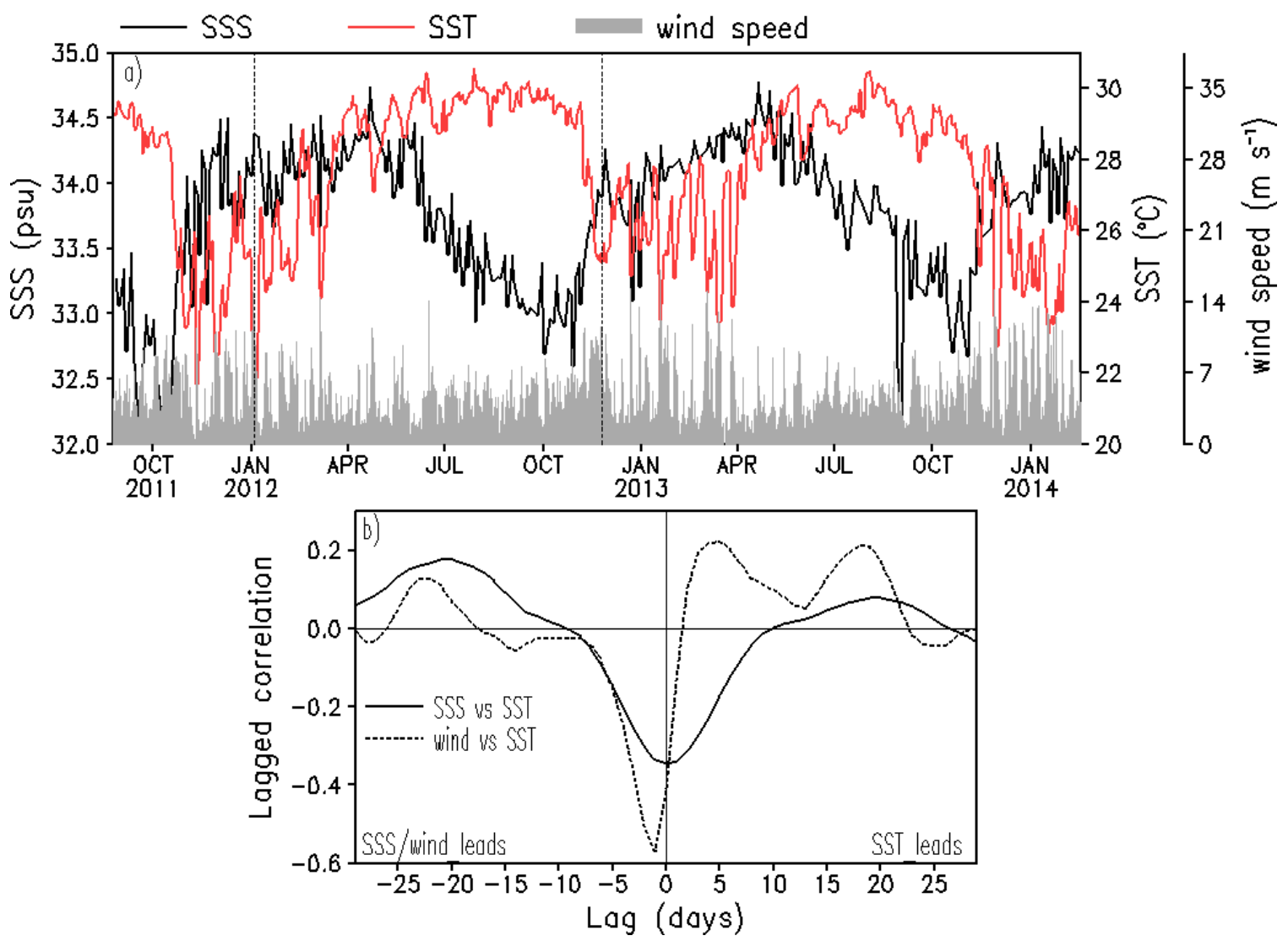

Figure 3. Variables averaged over the Gulf of Tahuantepec index region (see Fig. 1): (a) time series of SSS, SST, and wind speed; (b) lagged correlation coefficient for daily anomalies. Anomalies are calculated with respect to the seasonal cycle evaluated over the period for which Aquarius version 2.8.1 data are available (25 August 2011 through 17 February 2014). Two sample 'high SSS'-“cold SST”' events (peaking on 01/04/2012 and $11 / 25 / 2012$ ) are marked by vertical dashed lines in (a). 